\title{
Kualitas Perairan di Daerah Fishing Ground Nelayan Kerang di Pesisir Timur Kota Semarang
}

\author{
Chrisna Adhi Suryono ${ }^{*}$ dan Baskoro Rochaddi²
}

\author{
'Departemen IImu Kelautan, Fakultas Perikanan dan IImu Kelautan, Universitas Diponegoro \\ 2Departemen Oseanografi, Fakultas Perikanan dan Ilmu Kelautan, Universitas Diponegoro \\ JI. Prof. Soedarto, SH. Kampus UNDIP Tembalang, Semarang 50275 \\ Email : chrisna_as@yahoo.com
}

\begin{abstract}
Abstrack
This study aimed to assess the relationship between marine water qualities in bivalve fishing ground on easter part of Semarang coastal water. The result of study shows that the waters quality on those areas is still available for marine organism life. The water quality of dissolved oxygen between 5,6-6,2 ppm, water temperature $29,3-30,4{ }^{\circ} \mathrm{C}$, salinity $32-33,7$ ppt, pH 7,1-7,8, turbidity 20,2-42,5 NTU, and current velocity $0,15-0,55 \mathrm{~m} / \mathrm{sec}$. That water quality in the study areas compered with standard water for marinr life is still to suport marine bivalvia to live. Its is proved with some of bivalve found for examples (Anadara granosa A. pilula, A. Gubernaculum, A. Inaequivalvis, Pharella javanica, Paphia undulate, Marcia hiantina, Harvella plicataria, Mactra violacea dan Placuna placenta)
\end{abstract}

Keywords: Water quality, fishing ground, bivalve

\begin{abstract}
Abstrak
Hasil penelitian menunjukan bahwa kualitas air laut didaerah penelitian masih dikatan layak untuk kehidupan organisme laut. Konsentarsi DO (5,6-6,2 ppm), suhu air $(29,3-30,4$ $\left.{ }^{\circ} \mathrm{C}\right)$, salintas $(32-33,7 \mathrm{ppt}), \mathrm{pH}(7,1-7,8)$, kekeruhan $(20,2-42,5 \mathrm{NTU})$ dan kecepatan arus $(0,15-0,55 \mathrm{~m} / \mathrm{det})$. Bila dibandingkan dengan baku mutu air laut untuk kehidupan organisme laut secara keseluruhan masih layah terbukti ditemukanya beberapa jenis kerang seperti Anadara granosa A. pilula, A. Gubernaculum, A. Inaequivalvis, Pharella javanica, Paphia undulate, Marcia hiantina, Harvella plicataria, Mactra violacea dan Placuna placenta.
\end{abstract}

Kata Kunci : Kualitas air, fishing ground, kerang

\section{PENDAHULUAN}

Pesisir Semarang sampai Demak merupakan daerah fishing ground bagi nelayan tradisinal Semarang dan Demak untuk menangkap kerang, udang, rajungan maupun ikan. Meskipun sepanjang pesisir daratan daerah tersebut telah banyak beralih fungsi untuk kepentingan pelabuhan, industri maupun daerah reklamasi namun masih banyak nelayan yang tergantung dari perairan tersebut. Adanya kegiatan tersebut (aktivitas manusia) dan perubahan iklim tentunya akan berpengaruh terhadap kualitas perairan didaerah tersebut yang nantinya juga akan bepengaruh terhadap jenis dan jumlah hasil tangkapan yang diperoleh nelayan. Kualitas air suatu periaran sangat ditentukan oleh masukan material atau bahan ke perairan tersebut dan akan menentukan manfaat maupun produksi ekonomi perairan tersebut. Besarnya pengaruh masukan material ke lautan akan memberi dampak pada kualitas perairan maka dari itu banyak negara telah melakukan monitoring sepanjang tahun terhadap parairannya seperti China, Singapura, Kuwait, Amerika Serikat (Schiff at al, 2011; Devlin et al, 2015). Terlebih sekarang timbul permasalah baru terhadap ekosistem 
perairan dengan adanya fenomena berubahan iklim tentunya akan memberi dampak terhadap organisme yang ada didalamnya. Beberapa penelitian telah dilaporkan bahwa dengan adanya perubahan iklim akan menyebabkan degradasi terhadap kualitas air yang akhirnya berdampak pada keberadaan organisme (Rizzi et al., 2016,). Beberapa penelitian terdahulu di banyak negara terfokus pada status lingkungan perairan laut (Borja et al., 2011; HELCOM, 2010) namun beberapa penelitian tersebut masih belum menjelaskan bagaimana respon ekosistem laut terhadap aktivitas manusia dan perubahan iklim (Borja et al., 2013). Pada dasaranya penelitian dampak perubahan iklim terhadap ekosistem perairan masih ketinggalan bila dibandingkan dengan ekosistem daratan (Richardson and Poloczanska, 2008). Hal tersebut kemungkinan disebabkan terlalu luasnya ekosistem laut, kerumitan, variable dan kurangnya data time series yang relefan dan mencukupi (Pratchett et al., 2011). Maka dari itu penelitian ini bertujuan untuk mengkoleksi data kualitas air sehingga dapat dimanfatkan untuk memprediski dampak perubahan iklim dan aktifitas manusia terhadap kualitas air, terutama di perairan yang menjadi daerah penangkapan kerang.

\section{MATERI DAN METODE}

Materi yang digunakan dalam penelitian ini adalah air laut, yang diambil dari darah pesisir bagian timur Semarang yang merupakan daerah fishing ground kerang. Pengukuran kualitas 'air laut dilakukan di delapan titik stasiun dengan ulangan tiga kali dengan selang waktu satu minggu. Kualitas'air yang diukur meliputi okesigen terlarut (DO), suhu, salinitas, $\mathrm{pH}$, kekeruhan (diukur dengan menggunakan WQC Horiba) secara insitu sedangkan kecepanan arus diukur dengan menggunakan current meter secara insitu. Data yang dipeloreh berupa data kualitas'air ditabulasi dalam Microsoft exell untuk ditampilkan dalam bentuk grafik.

\section{HASIL DAN PEMBAHASAN}

Hasil pengukuran kualitas air (oksigen terlarut, $\mathrm{pH}$, salinitas, kekeruhan, kecepatan arus) menunjuk nilai yang masih dapat ditolelir maupun tidak untuk kehidupan organisme laut (Gambar 2). Batas terendah yang disyaratkan untuk untuk DO dalam air laut untuk kehidupan organisme laut adalah $>5 \mathrm{mg} / \mathrm{l}$, kekeruhan $<5$ NTU, pH 7 - 8,5, salinitas alami, suhu air laut alami (Keputusan Mentri Lingkungan Hidup no 51 tahun 2004). Sebenarnya angka angka tersebut tidak mutlak bagi kehidupan laut kecuali angka tersebut sangat ekstrim hal tersebut karena dilaut ada arus dan gelombang yang terus menerus bergerak secara dinamis yang dapat merubah kondisi tersebut setiap saat. Meskipun daerah tersebut banyak dialiri oleh

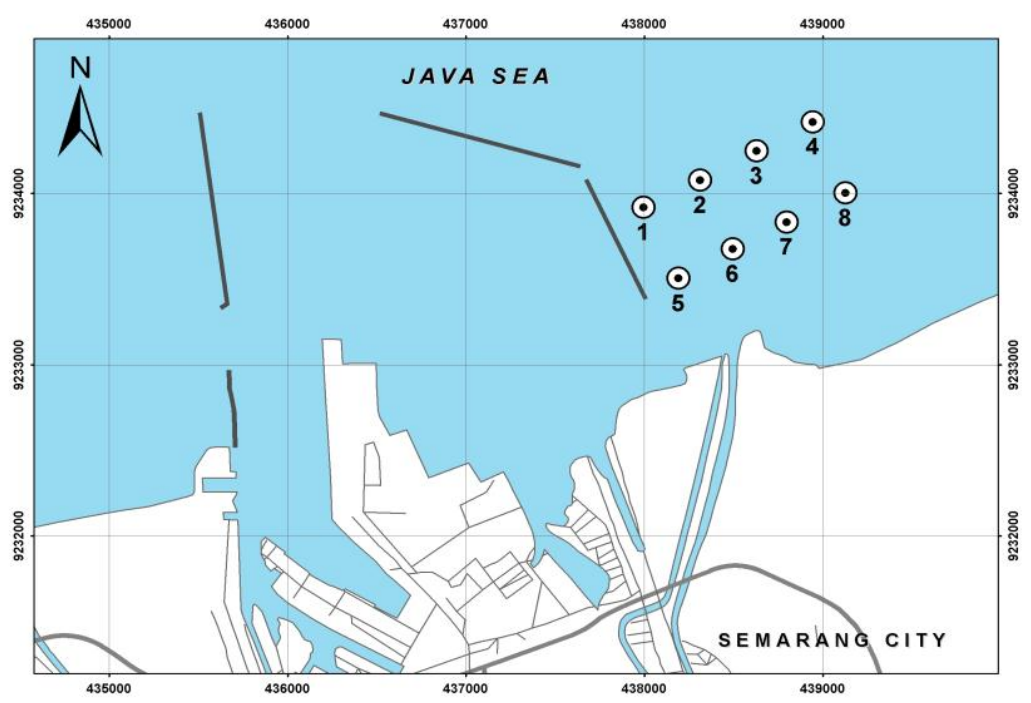

Gambar 1. Stasiun Penelitian di Pesisir Timur Kota Semarang 
beberapa sungai seperti Sungai Banjir Kanal Timur, Banger, Babon maupun Sri Mulyo yang kesemuanya mengalirkan baik nutrien maupun polutan padatan, tersuspensi maupun terlarut. Namun dengan besarnya masa air laut dan adanya arus laut yang dinamis maka semua masukkan yang masuk ke perairan laut dapat diencerkan sehingginga masih mampu ditolelir oleh organisme yang hidup didalamnya. Perairan tersebut meskipun sangat padat aktifitasnya seperti adanya daerah pelabuhan, penangkapan kerang, tempat pendaratan Ikan, industri, reklamasi, stock pile batubara maupun masukan buangan
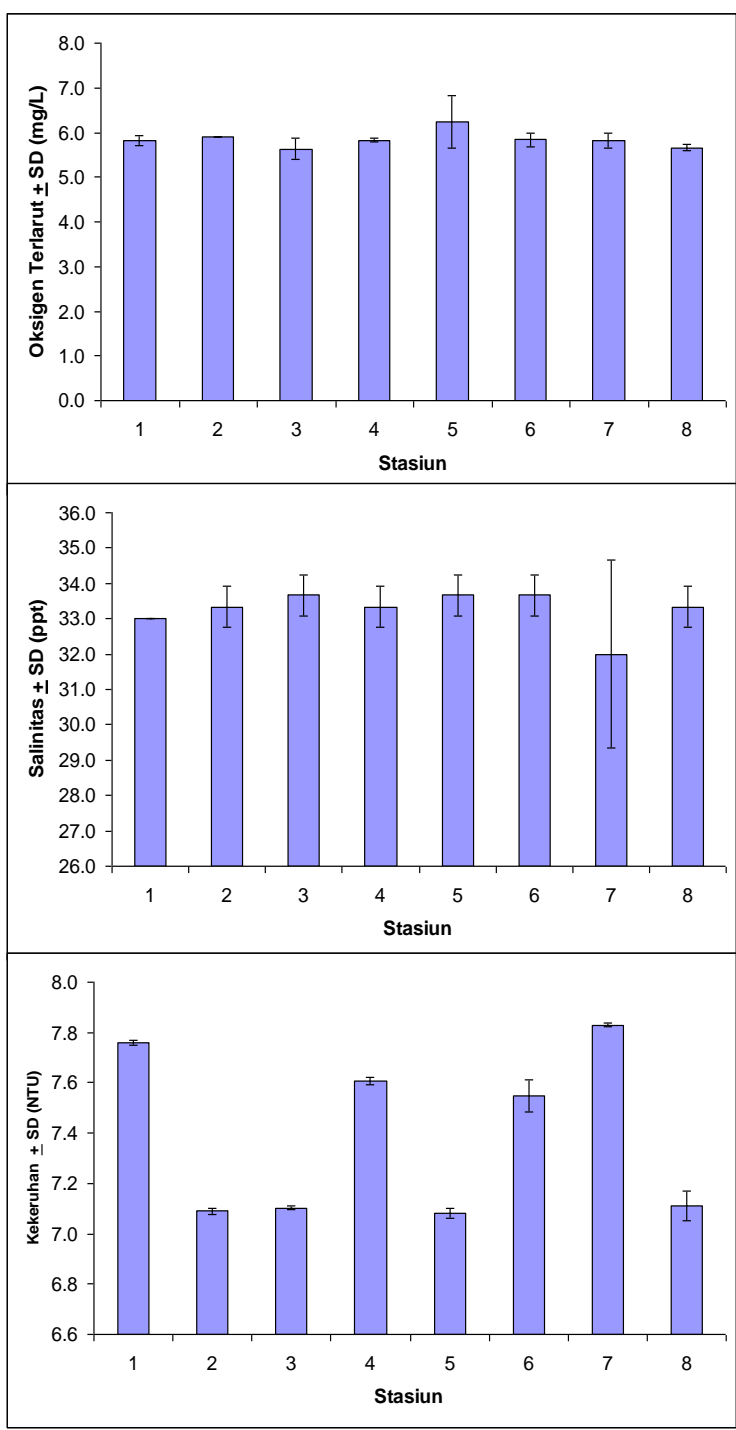

dari bebera sungai namun di perairan tersebut masih dapat menopang kehidupan organisme laut seperti kerang darah dan organisme benthik lainnya hal tersebut terlihat pada saat pengambilan sampel kerang tidak hanya didapatkan kerang darah Anadara granosa saja namun juga didapatkan jenis kerang lain seperti A. pilula, A. Gubernaculum, A. Inaequivalvis, Pharella javanica, Paphia undulate, Marcia hiantina, Harvella plicataria, Mactra violacea dan Placuna placenta. Hal ini membuktikan kualitas air di daerah tersebut cocok untuk kehidupan berbagai jenis kerang dan didukung dengan jenis sedimen, lumpur berpasir.
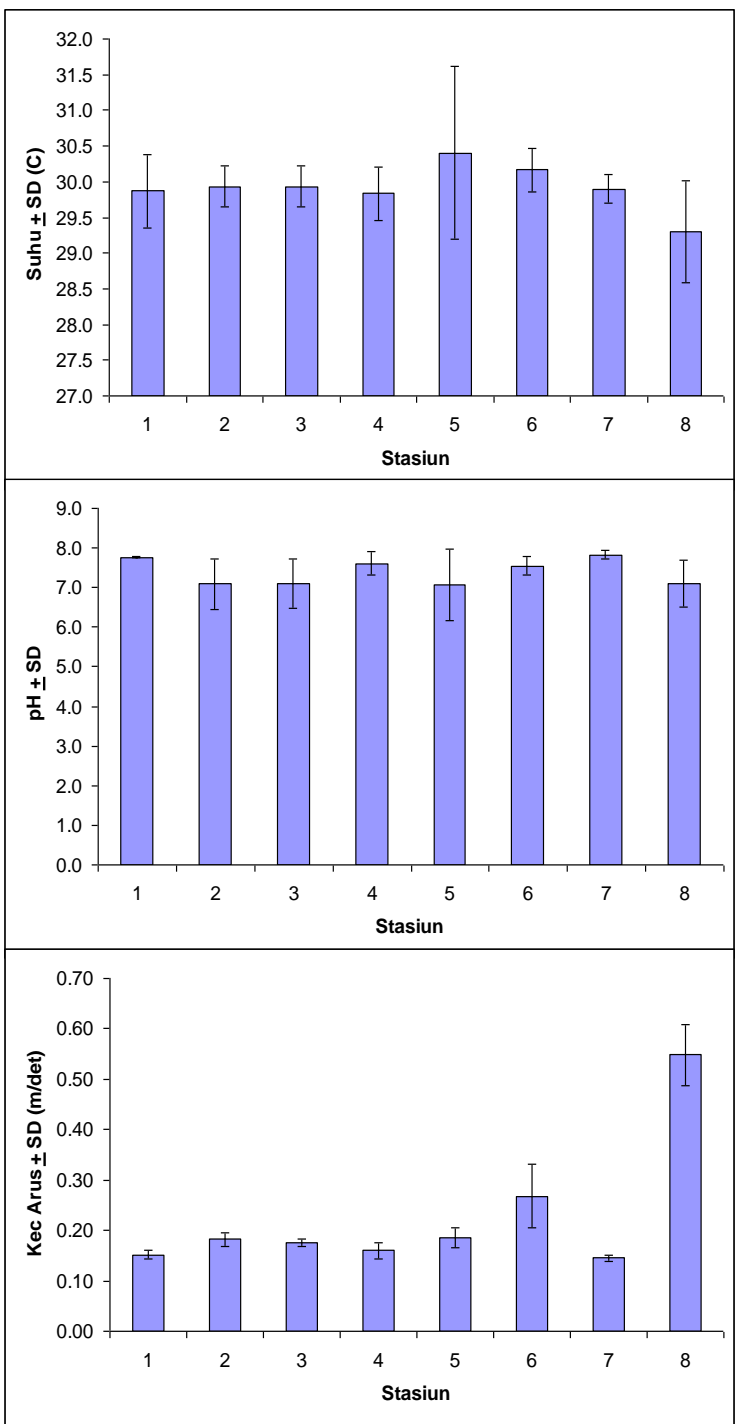

Gambar 2. Rata rata kualitas (DO, suhu, salinitas, $\mathrm{pH}$, kekeruhan \& kecepatan arus) \pm SD di lokasi penelitian 
Pemantauan kualitas air laut dilakukan secara terus menerus, karena perubahan yang ada dilaut maupun didarat melalui masukan air dari sungai sungai terjadi sangat cepat sepeti yang dilakukan di Kuwait (Devlin, at al 2015). Apalagi disekitar perairan tersebut banyak dimanfaatkan untuk berbagai kepentingan seperti alur layar, pelabuhan, pelabuhan, industri,pembangkit listrik, reklamasi maupun pemukiman. Masukan perbagai limbah dari aktifitas tersebut tentunya akan berpengaruh terhadap kualitas air dan direfleksikan terhadap jumlah dan jenis organisme yang ditemukan, Kondisi terebut juga terjadi di Kuwait (Abdullah et al., 2015).

Kualitas air memegang peranan sangat penting didalam kehidupan di laut terutama organisme yang menetap didasar perairan atau yang relatif lambat bergeraknya seperti kerang namun permasalahan terbesar saat ini adalah polusi dan perubahan iklim yang sangat berpengaruh terhadap kehidupan laut. Rizzi et al (2016) mengungkapkan bahwa adanya perubahan iklim meningkatkan tekanan terhadap ekosistem pesisir yang berakibat terjadinya penurunan kualitas ekositem perairan dikarenakan variasi biogeokimiawi dan fisika-kimia parameter yang berrubah seperti $\mathrm{pH}$, suhu dan salinitas. Meskipun dilokasi penelitian merupakan daerah tropis dimana suhu, salinitas dan $\mathrm{pH}$ relatif konstan sangat berbeda dengan apa yang dilaporkan Rizzi et al $(2016$,$) yang merupakan daerah$ temperate (dingin) dimana salinitas dan $\mathrm{pH}$ mudah berubah karena adanya pemanasan, penguapan, masukan air tawar yang besar dari kutup. Monitoring terhadap kualitas air laut di Indonesia biasanya terkait dengan adanya laporan pencemaran oleh aktivitas manusia dan hal tersebut sangat jarang dilakukan.

Banyak penelitian di daerah tropis terhadap kualitas air laut hanya terfokus yang terkait dengan eksositem tertentu seperti ekositem terumbu karang (Walther et al., 2002; Munday, 2004; Pandolfi et al., 2011 ), seagrass (Björk et al., 2008; Jorda et al., 2013; Koch et al.,2013) atau ikan (Roessig et al., 2004; Munday et al., 2009; Koehn et al., 2011) tanpa dihubungkan dengan kondisi ekosietem laut lainya. Pendekatan yang menyeluruh dalam pemantavan kualitas perairan di wilayah pesisir yang terpengaruh oleh dinamika tekanan antropgenik dan perubahan iklim telah dilakukan diberapa negara sperti laut Baltik, laut Utara, laut Adriatik Utara dan laut Hitam (Melvasalo, 2000). Secara terori pengelolaan ekosistem laut maupun pesisir di daerah tropis memang telah ada namun hal tersebut banyak mengalami banyak kendala. Namun penelitian kualitas air laut telah banyak dilakukan sperti yang daerah pesisir atau laut Semarang (Indonesia). Suryono et al. (2015) menginformasikan kontaminasi pstisida pada sedimen dan air laut yang berpengaruh terhadap kelimpahan hemawan makrozoobenthos di psisir Jepara. Sedangkan kualitas air laut di Semarang bila dilihat dari keberadaan logam berat ( $\mathrm{As}, \mathrm{Hg}, \mathrm{Cr}, \mathrm{Pb}, \mathrm{Cu}$ dan $\mathrm{Fe}$ ) di perairan Kecamatan Tugu Kota Semarang dapat dikatakan lebih tinggi dari baku mutu air laut untuk kehidupan biota laut (Suryono, 2016a). Lebih lanjut Suryono (2016b) menginformasikan bahwa logam berat $\mathrm{Cr}, \mathrm{Pb}$ dan $\mathrm{Cu}$ yang terdapat dalam sedimen laut di perairan Tugu Semarang memberi pengaruh terhadap jumlah jenis dan keanakeragaman organisme dasar.

Perairan Semarang yang tinggi kadar logam berat maupun pestisda masih ditemukan berbagai organisme benthik hal tersebut dikarenakan adanya peran arus laut yang selalu mngengencerkan dan menyebarkan polutan. Peran arus juga merupakan pembawa oksigen terlarut sehingga didaerah tersebut okeigen terlarutnya masih dikatakan tinggi dan layak untuk kehidupan organisme benthik seperti kerang. Kecepatan arus yang dalam lokasi penelitian antara 0,15-0,55 m/detik hal tersebut masih dikatakan tinggi.

\section{DAFTAR PUSTAKA}

Abdullah, A.D., Masih, I., Van Der Zaag, P., Karim, U.F., Popescu, I. and Al Suhail, Q., 2015. Shattal Arab River system under escalating pressure: a preliminary exploration of the issues and options for mitigation. Int. J. River Basin Manag. 13, 215-227. 
Björk, M., Short, F.T., McLeod, E., and Beer, S., 2008. Managing Seagrasses for Resilience to Climate Change. IUCN, Gland, Switzerland.

Borja, A., Elliott, M., Andersen, J.H., Cardoso, A.C., Carstensen, J., Ferreira, J.G., Heiskanen, A.,Marques, J.C., Neto, J.M., Teixeira, H., Uusitalo, L., Uyarra, M.C. and Zampoukas, N., 2013.Good environmental status of marine ecosystems: what is it and how do we knowwhen we have attained it? Mar. Pollut. Bull. 76, 16-27

Borja, Á., Galparsoro, I., Irigoien, X., Iriondo, A., Menchaca, I., Muxika, I., Pascual, M.,Quincoces, I., Revilla, M., Germán Rodríguez, J., Santurtún, M., Solaun, O., Uriarte, A.,Valencia, V. and Zorita, I., 2011. Implementation of the European Marine Strategy Framework Directive: a methodological approach for the assessment of environmental status, from the Basque Country (Bay of Biscay). Mar. Pollut. Bull. 62, 889-904

Devlin M.J., Massoud M.S.,. Hamid, S.A., A. Al-Zaidan,. Al-Sarawi, H., Al-Enezi, M.,. Al-Ghofran, L,. Smith, A.J., Barry, J., Stentiford, G.D, Morris, S., da Silva., E.T. and Lyons, B.P., 2015. Changes in the water quality conditions of Kuwait's marine waters: Long term impacts of nutrient enrichment. Mar. Pollut. Bull, $100,607-620$

HELCOM, 2010. Ecosystem Health of the Baltic Sea 2003-2007: HELCOM Initial Holistic Assessment. In: Baltic Sea Environment Proceedings, No. 122: 63.

Jorda, G., Marba, N. and Duarte, C.M., 2013., Climate warming and Mediterranean seagrass. Nat. Clim. Change 3, 3-4.

Keputusan Mentri Negara Lingkungan Hidup no 51 tahun 2014 tentang Baku Muta Air Laut

Koch, M., Bowes, G., Ross, C. and Zhang, X.H., 2013., Climate change and ocean acidification effects on seagrasses and marine macroalgae. Glob. Change Biol. 19 (1), 103-132. doi : 10.1111/j.1365-2486.2012.02791.x.

Koch, M., Bowes, G., Ross, C. and Zhang, X.H., 2013. Climate change and ocean acidification effects on seagrasses and marine macroalgae.
Glob. Change Biol. 19 (1), 103-132. doi : 10.1111/j.1365-2486.2012.02791.x.

Melvasalo, T., 2000. Regional marine environmental management and the GPA-LBA: perspectives and the need for scientific support. Ocean Coast. Manage. 43, 713-724

Munday, P.L., 2004. Habitat loss, resource specialisation, and extinction on coral reefs.Glob. Change Biol. 10, 16421647. doi :10.1111/J.1365-2486.2004.0 0839.X.

Munday, P.L., Dixson, D.L., Donelson, J.M., Jones, G.P., Pratchett, M.S., Dvitsina, G.V. and Doving, K.B., 2009. Ocean acidification impairs olfactory discrimination and homingability of a marine fish. Proc. Natl. Acad. Sci. USA 106, 1848-1852. doi : 10.1073/PNAS.08 09996106.

Pandolfi, J.M., Connolly, S.R., Marshall, D.J. and Cohen, A.L., 2011. Projecting coral reef futuresunder global warming and ocean acidification. Science 333, 418-422. doi : 10.1126 /science.1204794.

Pratchett, M.S., Bay, L.K., Gehrke, P.C., Koehn, J.D., Osborne, K., Pressey, R.L., Sweatman,H.P.A. and Wachenfeld, D., 2011. Contribution of climate change to degradation andloss of critical fish habitats in Australian marine and freshwater environments. Mar.Freshw. Res. 62, 1062-1081

Richardson, A.J. and Poloczanska, E.S., 2008. Ocean science: underresourced and under threat. Science 320, 12941295. doi : 10.1126/SCIENCE.1156129

Rizzi, J., Torresan, S., Critto, A., Zabeo, A., Brigolin, D., Carniel, S., Pastres R. and Marcomini, A., 2016., Climate change impacts on marine water quality: The case study of the Northern Adriatic sea., Mar. Pollut. Bull, 102, 271 - 282

Roessig, J.M., Woodley, C.M., Cech Jr. and Hansen, J.J., 2004. Effects of global climatechange on marine and estuarine fishes and fisheries. Rev. Fish Biol. Fish. 14, 251-275.

Schiff, K., Luk, B., Gregorio, D. and Gruber, S., 2011., Assessing water quality in Marine Protected Areas from Southern California, USA. Mar. Pollut. Bull, 62, $2780-2786$ 
Suryono, C.A a., 2016., Polusi logam berat antropogenik (As, $\mathrm{Hg}, \mathrm{Cr}, \mathrm{Pb}, \mathrm{Cu}$ dan $\mathrm{Fe}$ ) pada pesisir Kecamatan Tugu Kota Semarang Jawa Tengah. Jurnal Kelautan Tropis 19 (1): 37- 42

Suryono, C.A b., 2016., Akumulasi logam berat $\mathrm{Cr}, \mathrm{Pb}$ da $\mathrm{nCu}$ dalam sediment dan hubunganya dengan organisme dasaradi perairan Tugu Semarang, Jurnal Kelautan Tropis 19 (2): 143-149

Suryono, C.A., Suwartimah, K., Rochaddi, B dan Sarjito., 2015. Kontaminasi pestisida organoklorin pada sediment dan air laut dan pengaruhnya terhadap kelimpahan makrozoobenthos di pesisir Jepara. Jurnal Kelautan Tropis 18 (3):139-146

Walther, G., Post, E., Convey, P., Menzel, A., Parmesan, C., Beebee, T.J.C., Fromentin, J.,Hoegh-Guldberg, O. and Bairlein, F., 2002. Ecological response to recent climate change. Nature 416 , 389-395. doi :10.1038/416389 